\title{
ÉTICA PÚBLICA Y GOBIERNO LOCAL EN UN CONTEXTO DE CRISIS ECONÓMICA
}

\section{PUBLIC ETHICS AND LOCAL GOVERNMENT IN A CONTEXT OF ECONOMIC CRISIS}

\author{
Bernabé Aldeguer Cerdá \\ Universidad de Alicante. España/Spain \\ bernabe.aldeguer@ua.es
}

Recibido/Received: 20/12/2012

Aceptado/Accepted: 27/02/2013

\section{RESUMEN}

La caída de ingresos en el ámbito local como consecuencia, en gran medida, de la dependencia que han experimentado las Entidades Locales (EELL) españolas respecto del sector inmobiliario, confluye con un proceso de ajuste fiscal y con una creciente demanda de servicios sociales derivada de las ascendentes tasas de exclusión socioeconómica (menor consumo, cierre de empresas, desempleo). La crisis económica, acompañada de una crisis ética y de valores, remite a la emergencia de la Ética Pública como instrumento para la adopción de las políticas sociales y de refuerzo institucional y democrático. La búsqueda constante de legitimidad y de consenso, no tanto en relación al output de las políticas públicas sociales, sino sobre el propio procedimiento deliberativo y de diálogo en su definición y adopción, ubica a las EELL ante el reto de fortalecer el cuerpo político como premisa para la puesta en marcha y el desarrollo, con éxito, de procesos participativos y deliberativos. El fomento de las condiciones socioeconómicas precisas para garantizar la cohesión social, la libertad y la igualdad de oportunidades, devienen en retos que trascienden en mucho la literalidad y la urgencia de los balances contables y presupuestarios en un proceso de ajuste fiscal. El artículo repasa las principales tendencias y los retos emergentes en relación al papel de la Ética Pública en la adopción de las políticas públicas presupuestarias, de participación ciudadana y de inclusión social impulsadas desde las instituciones de gobierno local. Todo ello, en un contexto de crisis económica, progresivo debilitamiento social, ajuste fiscal del Sector Público local, desconfianza ciudadana respecto de las instituciones y creciente pluralismo axiológico.

\section{PALABRAS CLAVE}

Gobierno local, participación ciudadana, democracia deliberativa, cohesión social, ética pública, pluralismo axiológico.

\section{SUMARIO}

1. Introducción. 2. Crisis económica, crisis de valores. Causalidad y consecuencias. 3. Status Quo y Quo Vadis de las Entidades Locales en un escenario de crisis económica. 3.1. Status Quo: Las EELL frente a la crisis económica. Financiación y ámbito competencial. 3.2. Quo Vadis. Ajuste financiero y control de las cuentas locales. 4. El Papel de la Ética Pública frente a la crisis económica. 4.1. La ética en los procesos de adopción de decisiones frente a la crisis en el ámbito local. 4.2. Gestión de la integridad: estableciendo parámetros de monitorización, control y evaluación de la Ética Pública. 5. Conclusiones: Ethics in local government: it's more than not doing bad things. 6. Bibliografía. 


\begin{abstract}
The fall in public revenue by local governments, as a consequence of the finance dependence on the real estate sector, is combined with a process of fiscal adjustment and a growing demand for social services, which is result of rising socioeconomic exclusion rates (less consumption, business closures, and unemployment). The economic crisis, accompanied by a crisis of ethics and values, refers to the emergence of the Public Ethics as a tool for social policy-making and institutional strengthening. The incessant search for legitimacy and consensus, not so much in relation to the output of public social policies, but also about the dialog and deliberative process itself, puts local entities facing the challenges in the strengthening of the political body as a prerequisite for commissioning and developing successful participatory and deliberative processes. The promotion of socio-economic conditions to ensure social cohesion, freedom and equal opportunities, become a challenge that transcends the literalness and urgency of financial statements and budget processes in a fiscal adjustment context. The article reviews the main trends and challenges related to the role of Public Ethics in making public policy budget, citizen participation and social inclusion by local governments. All this, in a context of economic crisis, progressive social weakening, fiscal adjustment of the local public sector, public distrust for the institutions and growing axiological pluralism that is taken into account.
\end{abstract}

\title{
KEYWORDS
}

Local government, citizen participation, deliberative democracy, social cohesion, public ethics, axiological pluralism.

\section{CONTENTS}

1. Introduction. 2. Economic crisis, crisis of values. Causation and consequences. 3. Status Quo y Quo Vadis of Local Entities in a context of economic crisis. 3.1. Status Quo: Local Entities in a context of economic crisis. Funding and competence scope. 3.2. Quo Vadis. Funding adjustments and control of local accounts. 4. The roll of public ethical principles in a context of economic crisis. 4.1. Ethics and policy decision-making processes against economic crisis in the local scope. 4.2. Integrity Management: establishing parameters of control and evaluation of public ethical principles. 5. Conclusions: Ethics in local government: it's more than not doing bad things. Bibliography.

\section{INTRODUCCIÓN}

Son crecientes las reflexiones intelectuales y académicas, así como los informes profesionales y los códigos institucionales que en los últimos años, en el marco del impacto que ha tenido la crisis financiera sobre las Administraciones públicas, han abordado el alcance de una cierta crisis ética, de una crisis de valores, tanto en el origen como en las manifestaciones socioeconómicas y políticas de las actuales circunstancias de crisis poliédrica (Ramió, 2010). Asimismo, se ha evidenciado un progresivo interés por identificar, desde una orientación prescriptiva y normativa, la eventual contribución y el papel de los principios e instrumentos de Ética Pública y de Gestión de la Integridad a la hora de adoptar, diseñar y evaluar las políticas públicas impulsadas en el ámbito y nivel de gobierno local a la luz de los requerimientos de control del déficit público y ajuste financiero. El objetivo del presente trabajo, mediante una aproximación cualitativa consiste, en la identificación de la dimensión ética que se deriva de la presente situación de crisis socioeconómica tanto en sus causas, como en sus consecuencias. Desde una perspectiva institucional y normativa (Marsh y Stoker, 1997), el texto realiza un repaso de todas aquellas dimensiones a partir de las cuales, en el marco de las Entidades Locales (en adelante, EELL), resulte posible y preciso el 
impulso de políticas públicas y marcos institucionales que contemplando estándares de Ética Pública, permitan el fortalecimiento democrático deliberativo y la cohesión social.

\section{CRISIS ECONÓMICA, CRISIS DE VALORES. CAUSALIDAD Y CONSECUENCIAS}

¿En qué medida queda legitimado que frente a la presente situación de crisis poliédrica las respuestas y soluciones vengan dadas desde las Administraciones Públicas, total o parcialmente, desde la restitución, la invocación y el fortalecimiento de la Ética Pública? ¿En qué grado la Ética Pública aporta principios e instrumentos para la adopción participativa y deliberativa de las políticas públicas dirigidas a paliar las consecuencias socioeconómicas de la crisis desde una mayor cohesión e inclusión social y política? ¿Cómo, en definitiva, la Ética Pública puede contribuir a sentar las bases de un nuevo escenario institucional, democrático y axiológico que evite una eventual quiebra a futuro por la vía del fortalecimiento democrático, el fomento de la participación ciudadana y la adopción deliberativa de decisiones? Señala Cortina (2012) que: “(...) parece difícil creer que la falta de ética (de competencia, mesura, transparencia y responsabilidad) no tiene nada que ver con todo esto y que sólo la mala suerte económica nos ha llevado donde estamos" (Cortina, 2012), con lo que traer a primera línea de la reflexión el argumento acerca de la dimensión ética de la crisis resulta justificada y legitima propósitos como el representa el presente artículo. Bien es cierto, que los fundamentos axiológicos, tal y como precisa Dallmayr (1974), vienen dados en la actualidad por una suerte de contemporánea atrofia de la aptitud para el razonamiento moral práctico bajo parámetros de claro escepticismo ético en el marco liberal-pluralista de las sociedades industriales de Occidente (Dallmayr, 1974), siendo el pluralismo, en cualquier caso, un reflejo y claro fundamento ontológico de los sistemas políticos de Occidente (Blokland, 2001). Obviando la cuestión central acerca de la crisis de confianza que afecta a las democracias representativas de Occidente (Crozier, Huntington y Watanuki, 1975; Pharr, Putnam y Dalton, 2000; Ehrich, Cranston y Kimber, 2004; Hirasuna, 2010), resulta conveniente traer a colación planteamientos como el de Whiteley, P. (2011) quien, a partir del proyecto "Are Britons Getting More Dishonest?”, advierte que: "If social capital is low, and people are suspicious and don't work together, those communities have worse health, worse educational performance, they are less happy and they are less economically developed and entrepreneurial" (Whiteley, 2011). Capital social, valores, democracia y desarrollo económico son variables de incuestionable engarce explicativo. De este modo, la crisis financiera ha venido siendo caracterizada, en cuanto a sus causas, por una crisis de valores, por una crisis ética, debido a la inobservancia de ciertos principios éticos, de conducta y comportamiento por parte de directivos y titulares de los máximos órganos y niveles de responsabilidad, tanto en el ámbito del sector privado como en el del público. Máxime cuando: "( ...) both the internal and external environments of public administration have to be managed responsibly, so that citizens enjoy optimal benefits" (Dorasamy, 2010). Cabe enumerar, en este punto, más allá de las propias instituciones públicas, a los reguladores-supervisores financieros y a las corporaciones privadas; a saber: entidades financieras, fondos privados de inversión y de capital riesgo, agencias de rating, brokers, entre otros (McDowell. 2000; Hendry, 2004; Vitell y Ramos Hidalgo, 2006; Tsalikis y Seaton, 2007; Ruiz Garito, 2012). 
En el estudio de las relaciones entre los sistemas económicos y las estructuras axiológicas (en un nivel ético, religioso o ideológico), son de obligada referencia los clásicos y germinales esquemas formulados por M. Weber y K. Marx. Weber abordaría la relación entre la religiosidad racional del protestantismo ascético de corte calvinista, como base para el espíritu del capitalismo (la mentalidad económica que vendrá a configurarse en la edad moderna), "la vida económica capitalista" y la configuración del trabajo como profesión (Abellán, 2010). La conclusión de Weber, transcrita por Abellán (2010) es que: “el modo de vida racional sobre la base de la idea de profesión, que es uno de los elementos constitutivos del espíritu capitalista, y no sólo de éste sino de la cultura moderna, nació del espíritu del ascetismo cristiano" (Abellán, 2010; Weber, 2010). Marx, en Ideología Alemana, expondrá distinta relación causal, en el marco de la perspectiva materialista de la historia, y en virtud de la cual: “(...) la manera en que los hombres organizan la producción social y los instrumentos que para ello emplean constituye la base real de la sociedad -su estructura- y ella condiciona el conjunto de la vida intelectual, política y social" (Guiu, 1999). Es pues, recurrente y plausible, una aproximación al modo en que un acontecimiento de características e implicaciones aparentemente económicas en exclusividad, como es la actual crisis financiera, puede estar relacionada, en distinto grado y naturaleza, a causas dispositivas y a consecuencias derivadas de naturaleza axiológica.

En el escenario de las corporaciones privadas, en particular las del sector financiero, se han venido formulando numerosas reflexiones y propuestas concretas con objeto de generar códigos de conducta, de buenas prácticas y buen gobierno corporativo conforme al paradigma de la responsabilidad social corporativa. El foco de atención ha venido dado por la preocupación en promover la generación y asunción de prácticas y principios éticos bajo una visión de largo alcance, con objeto de evitar los efectos perversos de las exclusivas motivaciones lucrativas basadas en el corto plazo y en la obtención de beneficios inmediatos a costa de la integridad (Ameer y Othman, 2011). En última instancia, tales investigaciones convienen en que: “(...) even though corrupt practices may offer short-term economic benefits, there is a direct correlation between unchecked corruption and stifled development over the long term" (Hirasuna, 2010). Estos bosquejos han permitido evocar y proponer prácticas en el ámbito de la gestión y el desempeño empresarial privado destacando la importancia de la ética como un elemento fundamental de la orientación profesional, y como clave de futuro y sostenibilidad, para auditores y líderes empresariales. En virtud de tal proposición, Kidder (1995) dirige su atención hacia la construcción de un moral glue que permita armonizar los fundamentos éticos profesionales -deontológicos- en el ejercicio de las funciones de auditoría y control corporativo y empresarial (Sadowski y Thomas, 2012) o, lo que Cortina vendría a denominar, una ética global que materialice "el sueño kantiano de una comunidad ética cosmopolita, regida por leyes morales comunes" (Cortina, 2002). Ruiz Garijo (2012) expone la noción de la Responsabilidad Social Empresarial como un factor clave en periodos tales como la presente crisis económica, destacando la idea de que para generar beneficios, las corporaciones: “(...) además de tomar decisiones adecuadas, deben comportarse de forma ética" (Ruiz Garijo, 2012). Si bien, a efectos del presente artículo, resulta preciso hacer constar, en última instancia, la divergencia entre los códigos de ética en el sector privado y los propios del sector público, bajo la premisa de que "pensar en gestionar lo público como una empresa cuando se trata de algo diferente es una concepción errónea y obsoleta" (Canales, 2011). En este sentido, Hoogland y Whitaker (1993) explican que mientras los códigos del sector privado generan un sentido de la responsabilidad hacia la profesión y contribuyen a generar autonomía profesional, los códigos en el sector público 
enfatizan la responsabilidad pública y ayudan a crear public accountability. En la presente situación de deterioro axiológico, y como punto de partida para su reversión, se han venido realizando esfuerzos para identificar las conductas de: “(...) codicia, engaño, imprudencia, arrogancia, conflictos de intereses, fraude, incentivos perversos (...)" (Argandoña, 2010) o, siguiendo la enumeración de la OCDE (2009), prácticas tales como: 1) "Corruption including bribery, kickbacks, nepotism, cronyism and clientelism. 2) Fraud and theft of resources, for example through product substitution in the delivery which results in lower quality materials. 3) Conflict of interest in the public service and in post-public employment. 4) Collusion. 5) Abuse and manipulation of information. 6) Discriminatory treatment in the public procurement process. 7) The waste and abuse of organisational resources". (OCDE, 2009). Conductas que vulneran y dinamitan los fundamentos axiológicos y normativos de una gestión pública -pero también privada- que anteponga la integridad, el interés general y la sostenibilidad frente a cualesquiera otros estándares que hagan peligrar las bases que legitiman la función teleológica de las instituciones: la satisfacción, consecución y mejora del interés general.

\section{STATUS QUO y QUO VADIS DE LAS ENTIDADES LOCALES (EELL) EN UN ESCENARIO DE CRISIS ECONÓMICA}

\subsection{Status Quo. Las EELL frente a la crisis económica. Financiación y ámbito competencial}

La crisis económica está manifestando su más destacada impronta en el ámbito de las EELL y, en general, en el escenario multifacético, complejo y heterogéneo de las Administraciones públicas propias del nivel de gobierno local español: “(...) la reducción drástica del déficit fiscal, el agotamiento de un modelo productivo insostenible, así como la delicada situación financiera por la que atraviesan todas las Administraciones Públicas (estatal, autonómicas y locales) y la caída de ingresos fiscales, como consecuencia de la crisis, están impactando con una fuerza inusitada sobre el sistema financiero de los Gobiernos locales" (Jiménez Asensio, 2011). La caída de los ingresos de todas las Administraciones públicas debido a las recesiones que se vienen sucediendo en el contexto español (2008 y 2012) como correlato sucesivo de la crisis financiera internacional a partir del año 2008, se une a los efectos de la dependencia fiscal por parte de las EELL respecto del sector inmobiliario (Font y Galán, 2008). A ello, cabe unir la deriva de la crisis de deuda pública y la falta de crédito, proyectando así un amplio espectro de profundos problemas financieros en el ámbito local que se une a la ya endémica insuficiencia financiera de las EELL (Salvador Crespo, 2009), y con consecuencias que trascienden hacia la propia configuración institucional. El despliegue y la profundización en las políticas de democratización y de cohesión social, en tanto que expresión materializada de las éticas aplicadas (Cortina, 2007; Aranguren, 2011), resulta toda una prioridad estructural en un escenario caracterizado por: 1. La gestión de la urgencia y de la escasez (Jiménez Asensio, 2011). 2. El incremento en los índices de desconfianza ciudadana y de resentimiento (Pollit, 2010) con respecto a las instituciones (tanto privadas, - v. gr., financieras-, como públicas), junto con un deterioro de las variables ligadas a la evaluación de la clase política, los partidos políticos y los cada vez menores índices de interés político y eficacia política subjetiva. 3 . La creciente pluralidad, complejidad y fragmentación axiológica, la emergencia de nuevos “cleavages" (Torcal, 1989; Inglehart, 1991) y el empoderamiento de postulados ideológicos 
que cuestionan la democracia como forma de abordar la gestión del conflicto en que, ontológicamente, consiste la articulación de la acción política. 4. Crecientes tasas de exclusión social y empobrecimiento fruto de la crisis económica, que afectan a la cohesión del cuerpo político en tanto que premisa para el desarrollo de los procesos democráticos y de participación deliberativa en la adopción de políticas públicas. Generación, como consecuencia, de una creciente conflictividad e inestabilidad social, y una mayor demanda de servicios públicos (Font y Galán, 2008). 5. Un escenario de las EELL dado por: 5.1. Estructurales insuficiencias en el sistema de financiación para hacer frente a las demandas ciudadanas más inmediatas y al ejercicio fáctico de las "competencias impropias". 5.2. Una nueva configuración en las relaciones entre el gobierno central y las EELL dados los requerimientos de las medidas de ajuste fiscal en curso. 5.3. Un escenario de incertidumbre respecto de las eventuales y recientes reformas a emprender en el ámbito competencial de las EELL, la extensión de su Sector Público y la configuración institucional de los órganos de gobierno y representación (v. gr., reducción en el número de concejales). A la luz de todo ello, la generación y sostenimiento de un cuerpo político sólido, bajo la premisa de una fuerte cohesión socioeconómica, deviene en condición ineludible para la consolidación y la viabilidad de procesos participativos, de democratización y deliberación, no sólo para abordar la adopción, implementación y evaluación de políticas públicas, sino, fundamentalmente, para emprender la edificación deliberativa y discursiva de esquemas axiológicos y de generación de significado.

Ante la falta de adecuados instrumentos de financiación que permitieran dar plena vigencia al principio de suficiencia financiera en el marco de la autonomía local, las EELL han acabado dependiendo de los impuestos y tasas ligadas al sector inmobiliario y de la construcción, cuyo desplome ha supuesto la desfiscalización de municipios y Diputaciones Provinciales. El resultado deviene en unas EELL en pleno proceso de ajuste financiero y de reforma institucional, en un modelo de competencias "impropias" derivado del desajuste entre los ámbitos materiales de gestión atribuidos a las EELL conforme a la Ley 7/1985, de 2 de abril, Reguladora de las Bases del Régimen Local de una parte, y la ejecución presupuestaria que de facto efectúan las EELL en la satisfacción de las demandas ciudadanas más inmediatas.

En tal escenario, se viene desarrollando el debate doctrinal acerca de las formas de racionalizar la gestión de los recursos en las EELL, formulándose dos alternativas: las fusiones de municipios (amalgamation) y las soluciones supramunicipales y de coordinación entre Administraciones de distinto o igual nivel en relación al local. Ambas fórmulas implican diferencias significativas de corte institucional en cuanto a los procesos legitimación, de accountability y en la propia prestación de los servicios públicos. De acuerdo con Tomàs y Medir (2012), mientras las fórmulas de cooperación intermunicipal suponen la puesta en marcha de herramientas voluntarias de cooperación (planes estratégicos y redes informales) que pueden llegar (o no) a institucionalizarse (v. gr., consorcios), el modelo de amalgamation implica, en el escenario de las áreas metropolitanas, efectos negativos en cuanto a: 1 . La gobernanza de dichas áreas; 2. Los procesos de legitimación; y, 3. La propia prestación de los servicios públicos (Tomàs y Medir, 2012). Además, para el caso abordado por Okamoto (2012), los procesos de amalgamation han supuesto un alejamiento de las sedes municipales respecto de las áreas periféricas y de los núcleos de población más distantes de las nuevas ubicaciones, no sólo de sedes oficiales, sino también de los colegios electorales (Okamoto, 2012). En todo caso, en un contexto de extraordinaria competitividad, ajuste financiero y reordenación institucional, la cooperación constituye un 
factor clave para garantizar las supervivencia de las instituciones y permitir a las EELL de menor tamaño la posibilidad de entrar a formar parte de una masa crítica institucional; a saber: "en este sentido es muy importante de cara a unos buenos servicios públicos que las administraciones cooperen (...)" (Ramió, 2010).

\subsection{Quo Vadis. Ajuste financiero y control de las cuentas locales}

Los períodos de crisis financiera como el presente, han supuesto históricamente la puesta en marcha de distintos procesos de transformación administrativa e institucional, acompañados o no de reformas estructurales o sistémicas (Pollit, 2010), circunstancia que cobra especial relevancia en un escenario de crisis económica a largo plazo (Rodríguez Álvarez, 2010; Jiménez Asensio, 2011). En el presente epígrafe nos proponemos un breve repaso por las reformas institucionales que, al albur de los procesos de ajuste financiero, están produciéndose en el ámbito de las EELL españolas bajo con la iniciativa de la Administración central (Gobierno de España), a través del Ministerio de Hacienda y Administraciones Públicas. Uno de los ámbitos de especial notabilidad ha venido dado por los cambios en el régimen de control de la gestión financiera y presupuestaria de las EELL. Así, a lo largo de los últimos años, se han venido adoptando distintas medidas atribuidas a los habilitados estatales en relación a: 1. Elaboración del informe anual sobre el cumplimiento del Objetivo de Estabilidad Presupuestaria y seguimiento de los Planes Económicos Financieros (Real Decreto 1463/2007, de 2 de noviembre, por el que se aprueba el reglamento de desarrollo de la Ley 18/2001, de 12 de diciembre, de Estabilidad Presupuestaria, en su aplicación a las entidades locales); 2. Informe sobre el cumplimiento del Plan de Saneamiento para el endeudamiento extraordinario (Real Decreto Ley 5/2009, de 24 de abril, de medidas extraordinarias y urgentes para facilitar a las Entidades Locales el saneamiento de deudas pendientes de pago con empresas y autónomos); u, 3. Obligación de suministrar documentación a la Base de datos Nacional de Subvenciones (Real Decreto 887/2006, de 21 de julio, por el que se aprueba el Reglamento de la Ley 38/2003, de 17 de noviembre, General de Subvenciones). Las medidas de ajuste financiero y de control del déficit público en el ámbito de las EELL, a partir de la reforma del artículo $135 \mathrm{CE}$ y de la aprobación de la Ley Orgánica 2/2012, de 27 de abril, de Estabilidad Presupuestaria y Sostenibilidad Financiera, han supuesto una profunda transformación en las formas de adopción de decisiones presupuestarias, y en las prescripciones relativas a la capacidad de los Interventores en el control financiero (Blosca López, 2010).

De esta forma, el Real Decreto-Ley 4/2011, de 24 de febrero, ha implicado: 1. La identificación de las obligaciones pendientes de pago a los contratistas (art. 2). 2. El incremento de los niveles de endeudamiento de las EELL debido a la suscripción de las correspondientes operaciones de crédito adoptadas para la financiación de tales obligaciones. 3. La obligación de aprobar un plan de ajuste "(...) al objeto de garantizar la sostenibilidad financiera de la operación" (Exposición de Motivos), reteniéndose la participación en los ingresos del Estado a todas aquellas EELL que no hayan elaborado tal Plan de Ajuste. 4. El incremento de tasas e impuestos, así como la reducción de gastos ligados a diferentes conceptos presupuestarios y servicios públicos, con objeto de garantizar la viabilidad de la operación de crédito (art. 7.2). 5. Un incremento de la capacidad de supervisión por parte de la Administración central, por cuanto se refiere a la evaluación favorable del Plan de Ajuste por parte del Ministerio de Hacienda y Administraciones Públicas y por cuanto tiene que ver con las sanciones establecidas en caso de incumplimiento de las obligaciones establecidas, para cuyo seguimiento se faculta al Interventor (Real Decreto-Ley 7/2012, de 9 de marzo) en 
orden a que, anualmente, se eleve al citado Ministerio un informe anual sobre ejecución del plan de ajuste. 6. La disminución ostensible de los márgenes de disposición económica y presupuestaria por parte de las EELL durante el plazo temporal en que se extienda la operación de endeudamiento a largo plazo. 7. La posibilidad de introducir reformas estructurales en el entramado institucional de la correspondiente Entidad Local ("El Plan de ajuste podrá incluir modificación de la organización de la corporación local”, art. 7.3).

Este escenario remite al modo de identificar el punto de equilibrio entre los requerimientos tecnocráticos en el proceso presupuestario de una parte, y la deliberación democrática y ciudadana acerca del Presupuesto y sus bases de valores (Ho, 2000) involucrando conjuntamente, de esta forma, el democratic ethos y el technocratic and bargaining ethos (Wildasky, 1974). Una pléyade de estudios han puesto de manifiesto evidencias empíricas acerca de casos en los que se han establecido instrumentos para la medición de finantial performance data y la importancia de que estos consten y sean utilizados en los procesos presupuestarios (Jordan y Hackbart, 1999; Melkers y Willoughby, 2005; Beckett-Camarata, 2009). "The importance of such measures is that CAFRs are audited and, consequently, data from those reports used in financial performance reporting would be deemed credible and not be viewed with the same suspicion as other self-reported performance data may be" (BeckettCamarata, 2009).

Desde el punto de vista de los dilemas éticos, cabe señalar: 1 . La rapidez y urgencia de los plazos temporales en que tales medidas se han puesto en marcha, han dificultado per se, la puesta en marcha de mecanismos deliberativos y participativos, e incluso a nivel institucional, por cuanto el Plan de Ajuste ha sido elaborado desde los propios servicios de intervención, y no por el propio gobierno local. 2. De esta forma, la gestión de la escasez se ha producido bajo parámetros de escasa audiencia ciudadana y limitada capacidad institucional por parte de los propios gobiernos locales y de las Corporaciones en su conjunto (Pleno). 3. Los Planes de Ajuste, de esta forma, suponen un condicionamiento que encorseta las capacidades de decisión a largo plazo, introduciendo una rigidez que resulta contraproducente con respecto a los procesos deliberativos de elaboración presupuestaria y de priorización de inversiones, ingresos y gastos. Máxime, cuando una reducción presupuestaria de un determinado porcentaje, acaba quedando afectada por mor de un efecto multiplicador, afectando en un grado mucho más elevado a: “(...) las capacidades de diseño y gestión de las políticas y de los servicios de una unidad administrativa sectorial" (Ramió, 2010).

En última instancia, las políticas presupuestarias llevan implícitas, no sólo problemáticas contables y jurídicas, sino también dilemas de indudable trascendencia ética, máxime considerando el carácter estructural y a largo plazo de las decisiones que en la actualidad se vienen adoptando. Así lo ponen de manifiesto Franklin y Raadschelders (2004) al abordar, desde un estudio de caso (gobierno local de Oklahoma) las implicaciones y los day-to-day budget dilemmas que constantemente se manifiestan en los procesos presupuestarios. El proceso de diseño y ejecución presupuestaria implica una ethics-in-action que orienta los procesos de decisión en los que cabe dilucidar y optar por una entre múltiples opciones de elección en las que entran en juego valores distintos tales como: “(...) efficiency, political responsiveness, preserving the public interest over others. It is not a simple matter of determining what constitutes a right versus a wrong allocation decision, instead choices must be made between competing "right" choices" (Franklin, y Raadschelders, 2004). Pollit (2010) pone de manifiesto las implicaciones éticas de los procesos presupuestarios, máxime en period de recortes: "It is the process of making those cuts, and how they are presented, 
that raise ethical issues -and issues which have probably sharpened in recent years" (Pollit, 2010). Respecto de la contribución de la ética a la consecución de los principios de eficiencia en el seno de las Administraciones públicas, Diego Bautista (2009), al responder a la pregunta de “¿Por qué es rentable para un Estado la ética pública?”, señala que: "la ética aplicada a los servidores públicos contribuye a forjar una cultura por el servicio que eleva la responsabilidad y eficiencia en el desempeño de los cargos" (Diego Bautista, 2009). La motivación y la conciencia de la posición clave que ocupan los servidores y empleados públicos en el escenario de las instituciones públicas, resulta clave para una utilización de los recursos públicos destinada, única y exclusivamente, a la satisfacción del fin que legitima la existencia de la Administración pública: el interés general, el bien común.

\section{EL PAPEL DE LA ÉTICA PÚBLICA FRENTE A LA CRISIS ECONÓMICA}

\subsection{La ética en los procesos de adopción de decisiones frente a la crisis en el ámbito local}

Que la crisis no es, en exclusividad, económica, sino que implica, poliédricamente, distintas facetas, establece el imperativo analítico y conceptual de aproximación a la misma desde una perspectiva institucional y normativa-prescriptiva. Las circunstancias económicas remiten a la forma en que el deterioro socioeconómico puede, eventual o ciertamente, derivar en profundas transformaciones en cuanto a los argumentos de cuestionamiento de la democracia, que germinan y fructifican en escenarios de desmembramiento socioeconómico y ético frente a una percepción negativa en cuanto a la vigencia del diálogo y la deliberación democrática en la resolución de problemas a los que se exige una rápida resolución (Ewing, 1941). De acuerdo con Sanmartín (2012): “(...) recordemos que el propio Linz, además de otros brillantes expertos, ha señalado entre las condiciones imprescindibles para el éxito de los fascistas, "la crisis, la corrupción y la inestabilidad de los gobiernos democráticos" (Sanmartín, 2012). Blockland (2001) advertirá cómo, ante los dinámicos y rápidos procesos de creciente pluralismo axiológico, la incertidumbre y la ansiedad colectiva acaban por manifestarse en el cuerpo político, de tal forma que: “(...) there is a danger that people will start to look for someone to impose a dictatorial order on the chaos" (Blockland, 2001). La discusión acerca de los fundamentos éticos sobre los que construir las soluciones participativas frente a la crisis económica, es más necesaria que nunca pero, sin embargo, también, más difícil. ¿En qué sentido? La falta de claridad normativa y axiológica que provoca la estructural pluralidad axiológica, junto con el deterioro en los índices de confianza en las instituciones, hace que no se puedan ofrecer respuestas inequívocas en un período, caracterizado por la gestión de la urgencia y la escasez, en el que, precisamente, se solicitan respuestas urgentes (Manheim, 1941; Blokland, 2001). De ahí que, frente a tal escenario, y retomando a Sanmartín (2012): "la mejor contestación a este peligro es la reafirmación de los principios de libertad y pluralidad, defendiendo activamente el sistema democrático, al tiempo que se profundiza en su expansión y mejora. Se trata de recuperar el axioma pronunciado por un erudito norteamericano: los problemas de democracia se resuelven con más democracia, nunca con menos" (Sanmartín, 2012). El problema, tal cual queda expuesto por Langford (1991), deriva en que hasta que la tormenta no se desata, no saltan las alarmas y el éxodo axiológico se manifiesta, no es cuando se trata de responder: “(...) by creating a new set of rules or resurrecting rules from some dust covered guidelines or codes of conduct (Langford, 1991). La cuestión nos exige a evaluar si, en determinadas ocasiones, no es ya 
demasiado tarde, no sólo para evitar, sino para paliar las manifestaciones de eventuales crisis de confianza y desafección, sino incluso para evitarlas. En última instancia: "The degree to which we can trust people to do their jobs properly and responsibly is at the root of the ethical challenge (Franklin, y Raadschelders, 2004). No sólo por una cuestión de efectividad a la hora de afrontar y solucionar las situaciones dadas en términos coyunturales y de concreción, sino por la propia configuración largoplacista que, dada la naturaleza del entramado ético, supone la función estructural y pedagógica de esta desde una perspectiva axiológica (Preston y Samford, 2002). El fortalecimiento democrático hunde sus raíces en una tesis basada en el compromiso ético por la vertebración axiológica de la sociedad en el marco de los consensos básicos en torno al diálogo y la deliberación. En este punto, un ejercicio ético del liderazgo y un impulso comprometido desde las élites con la promoción de la ética, deviene en una prioridad. De acuerdo con Ciulla (2004), la ética constituye el corazón del liderazgo, de modo que siendo esta un área de ética aplicada: "leadership ethics needs to take into account the research on leadership, and it should be responsive to the pressing ethical concerns of society" (Ciulla, 2004), a pesar de que: "normative theories of leadership, such as transforming leadership and servant leadership, are not well developed in terms of their moral implications. They require more analysis as ethical theories and more empirical testing" (Ciulla, 2004). Tal y como ha venido en señalar Canales Aliende (2002): "los que ocupan cargos públicos, deberían fomentar y apoyar estos principios con su liderazgo y su ejemplo (Canales Aliende, 2002). Reflexionar, pues, sobre la idoneidad, emergencia y oportunidad de la Ética Pública a la hora de legitimar y poner en marcha procesos participativos y de fortalecimiento democrático en el ámbito de la praxis administrativa y de la Gestión Pública, constituye en las circunstancias descritas, un aspecto de plena vigencia en los ámbitos profesional-deontológico, político-ideológico y académico. Resulta clave reflexionar, pues, sobre el papel y la emergencia de decisiones a impulsar desde parámetros crecientemente inclusivos y participativos de acuerdo con la lógica deliberativa y discursiva de la democracia en el ámbito local. Construir, producir y reproducir de forma deliberativa e inclusiva, los parámetros básicos de carácter axiológico que permiten dar forma y contenido a los instrumentos democráticos, constituye una garantía para dotar de legitimidad a cada una de las fases del ciclo de políticas públicas y para avanzar en la construcción de una Administración pública bajo estándares de buen gobierno y garantizando el derecho a una buena administración (Ávila Rodríguez y Gutiérrez Rodríguez, 2011).

\subsection{Gestión de la integridad: estableciendo parámetros de monitorización, control y evaluación de la Ética Pública}

A lo largo de los últimos años se han venido adoptando "(...) ethical codes, statements and other organizational machinery for regulating conduct" (Cowell, Downe y Morgan, 2011). La importancia de analizar los factores que permiten explicar la eficacia y el éxito de tales instrumentos, requiere de un ejercicio de concreción de tales estándares de Ética Pública. No obstante, distintos polos de tensión aparecen cuando se trata de articular sistemas de gestión de la integridad; a saber: A. Principios concretos y detallados (codificación) vs. Principios abstractos; o, B. Control y regulación punitiva vs. Concienciación-formación. Prospectivamente se viene planteando la necesidad de implantar sistemas que permitan evaluar los efectos negativos y positivos de los instrumentos de Ética Pública (Demmke y Moilanen, 2012). En este sentido, los factores que han determinado la efectividad e impacto del ethical framework en el caso británico local a partir del año 2000, vienen dados, conforme a Cowell, Downe y Morgan (2011) por: "The role of monitoring officers; the 
political and managerial leadership of the authority; the role of party groups; identification with the council; political structures and voice" (Cowell, Downe y Morgan, 2011). Los mismos autores destacan variables que, en otros casos, han explicado el fracaso de los desarrollos de codificación (v. gr., Sudáfrica), debido a: “(...) incomplete disclosures, a lack of standardization across authorities and a lack of institutional support", [Cowell, Downe y Morgan, 2011]). Para el caso Italiano, se han destacado como variables significativas en la implementación de marcos regulativos éticos, "the virtue of integrity, and the praxis of communication" (Giovanola, 2011). En el escenario estadounidense, Fattah (2011) identificará cuatro factores de extraordinaria significancia y capacidad explicativa en cuanto al control de la corrupción y la gestión de la integridad; a saber: 1. 'Democracy's principles, procedures, and processes; 2 . Communalization and institutionalization of profesional ethical standards; 3. The role of professional leadership training and recruitment; and, 4. Irrationalization of unethical behaviour" (Fattah, 2011). Lancer Julnes (2009) destaca la relevancia de la medición del rendimiento en la gestión pública para el apoyo de comportamientos éticos a cargo de electos, directivos públicos y funcionarios en tanto que: 1 . Herramienta de evaluación y conocimiento. 2. Control y supervisión. 3. Motivación y movilización, y, 4. Mejoramiento. La medición del desempeño público: “(...) offer(s) an opportunity for engaging citizens" (Lancer Julnes, 2009), en la medida en que permite disponer de indicadores de evaluación respecto de la gestión desarrollada, en orden a afrontar procesos deliberativos de carácter participativo e inclusivo que contemplen, además, la participación ciudadana en el proceso de performance measurement. Diego Bautista (2009) formula un Sistema Ético Integral (SEI) para la prevención de la corrupción que contempla cinco fases cronológicas y lógicas: 1. Identificación de la ética como materia prima. Deliberación, concienciación y voluntad política. 2. Asignación de un responsable, integración del equipo ético y misión institucional. 3. Preparación de los instrumentos de trabajo: un marco jurídico ético, un marco normativo de conducta -códigos de ética-, la literatura y el cine como instrumentos de acceso a la ética y de educación en valores, y la Ética Pública en el ejercicio profesional. 4. La operación del trabajo (implementación) mediante formación y la interiorización de los valores éticos deseables por parte de los servidores públicos. 5. Supervisión, control y evaluación, mediante participación ciudadana, sistema de sanciones ejemplares y mecanismos de transparencia y feedback entre las instituciones y la ciudadanía.

Según lo expuesto, la ética en abstracto no contribuye a identificar condicionamientos conductuales de directivos y miembros de organizaciones -y de las propias organizacionesen general. Por ello, siguiendo a Argandoña (2010), “¿Pudo la ética haber prevenido la crisis y puede evitar que aparezcan nuevas crisis en el futuro? Sí, pero no la ética en abstracto, sino la ética incorporada en los objetivos, estructuras y culturas de las organizaciones (...) y, por tanto, en las decisiones de sus directivos y empleados" (Argandoña, 2010). En este sentido, algunas orientaciones de medición y concreción vienen dadas por el Código de Buen Gobierno de la FEMP (2009), que prevé la creación de un Observatorio de evaluación de calidad democrática encargada del seguimiento y la evaluación respecto del grado de cumplimiento y aplicación del Código. En la misma línea, fue emitida la recomendación de la OCDE Building Public Trust: Ethics Measures in OECD Countries (2000), destinada a materializar y establecer parámetros que posibilitan, por su propia naturaleza concreta, monitorizar la vigencia y el cumplimiento de tales prescripciones éticas. En particular, sus recomendaciones son las siguientes: " 1 . Ethical standards for public service should be clear. 2. Ethical standards should be reflected in the legal framework. 3. Ethical guidance should be 
available to public servants". La tensión conceptual y práctica se patentiza cuando se trata de plantear la oportunidad de detallar normas de conducta que regulen la máxima cantidad posible de eventuales incumplimientos (Moore, 1981) o si, por el contrario, cabe decidirse por establecer vagos, amplios y generales principios éticos (evitando incluso la adopción de Códigos Éticos), cuya aplicación quedará bajo el criterio de concreción e interpretación, por parte de directivos, funcionarios, empleados públicos y electos, conforme a la dimensión interna de sus propios esquemas morales (Franklin y Raadschelders, 2004), en quienes recaerá la responsabilidad ética de ejecución e implementación (Atkin, 2003). Siendo la Ética Pública un claro objeto instrumental para la adecuada orientación de los procesos de decisión en el ámbito de la Gestión Pública y no una mera declaración de intereses o valores abstractos que podrían devenir en voluntarismos finalistas sin eficacia efectiva, resulta justificado proceder a su concreción y plasmación transversal en cada uno de los procesos de gestión y administración en orden a hacer viable y eficaz su vigencia y aplicabilidad.

Finalmente, ¿Cuáles son las posiciones sobre la idoneidad de establecer instrumentos de punición frente al incumplimiento de los Códigos de Conducta y Buen Gobierno con objeto de garantizar su cumplimiento y plena eficacia? La efectividad de tales arrangements, sin duda alguna, viene dada, en gran medida, por la existencia de sistemas de seguimiento, control y, en última instancia, de punición, más allá de la ya considerada cuestión acerca del grado de concreción. Entre quienes proclaman un control estricto de los comportamientos conforme a los estándares de conducta ética codificados, y quienes, por otra parte, abogan por relajar, en la máxima medida posible, todo control sobre el proceso decisional de electos y funcionarios (Anechiarico y Jacobs, 1994), es posible encontrar numerosos mecanismos e instrumentos que permitan garantizar la efectividad de los principios codificados. Conforme a Villoria (2011): “(...) es muy interesante comprobar cómo los códigos de ética, donde funcionan, se acompañan de una serie de instrumentos de apoyo para hacer efectivos los mismos" (Villoria, 2011). Así, hay quienes, para asegurar la efectividad de los principios de Ética Pública, proponen incrementar los controles propios de la garantía administrativa a la hora de evitar conductas tales como, entre otras, la arbitrariedad (Moe y Gilmour, 1995), y quienes apuestan por una sofisticación de los sistemas de accountability: “(...) defining who is responsible for what and developing comprehensive monitoring, reporting and evaluation systems. This is a means of preventing misdemeanours, or at least exposing them to scrutiny, including public scrutiny, after the fact" (Moe y Gilmour, 1995). Dado el complejo proceso de ajuste financiero y reforma institucional que ha afectado y que todavía planea sobre las EELL, una de las líneas fundamentales de análisis ha destacado la necesidad de introducir la imputación de responsabilidades en la gestión presupuestaria local como garantía para el cumplimiento de las prescripciones normativas al respecto. En particular, la remisión de la Cuenta General de las Entidades Locales (EELL) al Tribunal de Cuentas (TCu) o, en su caso, a los correspondientes Órganos de Control Externo (OCEX) de las Comunidades Autónomas (CCAA), constituye la clave de bóveda de la fiscalización ex post de las cuentas públicas locales, posibilitando el ejercicio de la función ontológica que corresponde al TCu en cuanto que Entidad Fiscalizadora Superior de la gestión económica del Estado y el Sector Público. ¿Cuáles son las recomendaciones propuestas? 1. Convergencia de las normativas del Estado y de las CCAA en cuanto al establecimiento de los plazos para la rendición de las Cuentas Generales para evitar las dos primeras consecuencias más arriba citadas (incumplimiento de plazos y divergencia en los niveles de exigencia). 2. Reducción de los plazos por cuanto la introducción de procedimientos informáticos para la elaboración y rendición de los estados contables “(...) no requieren plazos tan dilatados en el tiempo como los previstos en la 
normativa". 3. Ascender el adecuado cumplimiento de la rendición de cuentas a requisito inexcusable para "acceder a procedimientos de concesión de ayudas y subvenciones públicas". 4. Incoación de expediente disciplinario (estatal o autonómico) en caso de falta de rendición de las cuentas generales de las EELL, “(...) dirigido a depurar las responsabilidades pertinentes (...)". 5. Incluir en la cuenta general la "(...) información sobre las sociedades mercantiles participadas por más de una entidad local en proporción agregada superior al $50 \%$ pero en las que, sin embargo, no participa mayoritariamente ninguna entidad local de forma individualizada (...)". Estas recomendaciones, junto el cumplimiento estricto de las vigentes disposiciones sancionadoras sin esperar a futuras reformas, resultan necesariamente impulsadas y aplicables, pues en última instancia, la confianza en el sistema democrático y en los órganos constitucionales que lo articulan, viene dada por la transparencia y por la positiva percepción ciudadana de que existe un compromiso y un funcionamiento normalizado en el seno de las instituciones, de los cargos electos, de los funcionarios y de los directivos públicos, en la rendición de las cuentas públicas y en la efectividad de los procedimientos de accountability horizontal. Conforme Grimes y Bauhr (2012), "Transparency advocates maintain that greater Access to government information is the sine qua non of greater accountability and better government in the long term" (Grimes y Bauhr, 2012).

\subsection{La ética en la promoción de la cohesión social en tanto que premisa para el fortalecimiento democrático y del cuerpo político}

Las EELL han venido a hacerse cargo de innumerables áreas de gestión, bajo la fórmula fáctica de las competencias llamadas "impropias", por medio de las cuales tales entidades vienen haciendo frente a las necesidades ciudadanas en el ámbito socioeconómico, así como sosteniendo unos servicios públicos cuya demanda se incrementa fruto de las circunstancias de exclusión social, paro y debilitamiento de la actividad productiva y de las pautas de consumo. La realidad de deterioro social, en el escenario español, se manifiesta en distintos indicadores que testimonial tal escenario. Las políticas sociales y la reducción del gasto público ligado a la financiación de tales políticas, supone profundizar en la caída de los niveles de cohesión social: “(...) y la mayor fragilidad de determinados grupos de población, especialmente los inmigrantes" (Jiménez Asensio, 2011). Desde el punto de vista del impulso de los procesos participativos y democráticos, la ausencia de un cuerpo político erigido sobre índices equilibrados de cohesión social, hace desaparecer la condición previa de un cuerpo social vertebrado y cohesionado: “(...) elemento necesario para que los mecanismos funcionales de la deliberación democrática actúen con eficacia" (Menéndez Alzamora, 2012). La generación de oportunidades sociales en el ámbito de la estructura económica, supone la vertebración de oportunidades en lo político; a saber, en el escenario de la inclusión en el proceso deliberativo. Es así como Sen (2003) relaciona los factores de equidad y de eficiencia, los valores y las instituciones, por cuanto la generación de condiciones de libertad, igualdad y satisfacción de derechos socioeconómicos, permite la sostenibilidad económica, la creatividad cultural y, en última instancia, la inclusión política y la participación: "Las complejas interdependencias entre valores, instituciones y normas de comportamiento, así como entre la respectiva búsqueda de equidad en la distribución y eficiencia en la producción requieren una investigación más amplia de la que suele acordárseles" (Sen, 2003). De ahí la relevancia de construir ethical frameworks, no sólo en períodos de debilitamiento institucional o socioeconómico, sino también, y fundamentalmente, en aquellos lapsos temporales de expansión de las funciones estatales y de desarrollo 
económico. La generación de dichas oportunidades de participación e inclusión resulta premisa insoslayable para viabilizar y permitir la realización de la participación ciudadana deliberativa. De esta forma se avanza en la consecución del principio de equidad, antecedente cuya vulneración ha sido alegada por algunos de los críticos de la democracia deliberativa para justificar la irrealización de tal modelo democrático (Fraser, 1992). Así pues, el fortalecimiento del cuerpo social en tanto que fundamento del cuerpo político, resulta vital en el sentido de que la vertebración democrática deviene tanto de una mayor cohesión social como de una mayor calidad de la vida pública, dimensiones ambas en las que la Ética Pública constituye en eslabón clave (Bennet, et al., 1996). De ahí que el desarrollo, fomento y adopción de fuertes parámetros éticos resulte premisa ineludible para la legitimación y la estabilidad de gobiernos justos y democráticos. Siguiendo, en este punto, a Diego Bautista (2009): “(...) la ausencia de principios éticos en los representantes públicos crea gobiernos injustos y corruptos que en lo macroeconómico arruinan y endeudan al país y en lo microeconómico generan desigualdad social, desempleo y miseria” (Diego Bautista, 2009). En la misma orientación, Cortina (1998) sostiene que: "Globalizar la justicia es la tarea de una Ética Pública de las instituciones y las organizaciones, consciente de que la felicidad es cosa de las personas, incumbencia de cada ser humano" (Cortina, 1998).

La correlación entre los niveles de desarrollo socioeconómico, estructura social y redistribución de una parte, y la estabilidad y viabilidad democrática de otra parte, ha venido constituyendo una profusa línea de investigación testada teórica y empíricamente a través de distintos proyectos y estudios académicos. En este sentido, la obligada referencia de trabajos como el de Moore, (The Social Origins of Dictadorship and Democracy, 1966), viene a inaugurar un conjunto de trabajos que abordará, siguiendo el trabajo de Przeworski, et al., (1996), la significancia explicativa del nexo entre: A. El nivel de ingresos, la redistribución de la riqueza (igualdad) y el crecimiento económico (crisis o desarrollo); y, B. Las probabilidades de instauración, consolidación o riesgo y desaparición de un sistema democrático, evaluando, asimismo, factores propios del contexto internacional (propicio a la democracia y a la democratización) así como institucionales ligados, en especial, al parlamentarismo (Przeworski, et al., 1996). La más reciente cuestión formulada por Fukuyama (2012), Can Liberal Democracy Survive the Decline of the Middle Class?, arroja trazas acerca de la vulnerabilidad de una democracia liberal sustentada en una clase media, ahora erosionada por la reducción de ingresos, la falta de redistribución de la riqueza, la sustitución de las labores instrumentales de las personas por las máquinas-alta tecnología y por los efectos de la globalización en la estructura del mercado de trabajo (Fukuyama, 2012). Welzel, y Inglehart, R. (2009), tratando de abordar la cuestión acerca de What determines the emerge, survival, and development of democracy?, ponen de manifiesto, desde el enfoque de la cultura política, la correlación entre las condiciones de modernización socioeconómica y el desarrollo económico a partir de las orientaciones emancipadoras y los valores de un cuerpo social determinado. Weingast (1997), por su parte, pondrá énfasis en destacar que la estabilidad democrática depende: “(...) on a self-enforcing equilibrium: It must be in the interests of political officials to respect democracy's limits on their behaviour. (...). Selfenforcement of limits depends on the complementary combinations of attitudes and reactions of citizens as well as institutional restrictions" (Weingast, 1997). Las contribuciones académicas citadas abordan un conjunto de formulaciones que adquieren plena vitalidad en la presente circunstancia de crisis socioeconómica y de creciente pluralismo axiológico, permitiendo la iniciación de los planteamientos prescriptivos y normativos dirigidos a 
dilucidar el alcance de una situación de crisis en el marco de las democracias representativas occidentales.

Finalizamos el epígrafe con la brillante formulación de Manheim (1941), quien alude a la justicia social como un imperativo y requisito ineludible para los procesos de construcción deliberativa de los consensos políticos a partir de determinados valores básicos, debiendo recuperar las democracias su interés por los valores, en ciertas ocasiones ambiguos, pero asequibles para ensamblar la infraestructura normativa del cuerpo sociopolítico (Manheim, 1941). La determinación de los valores públicos en un escenario de fragmentación y pluralismo en cuanto a las fuentes morales, requiere de una cohesión social que dote de la suficiente fortaleza al cuerpo político, de modo que, como expone Blokland (2001): "In order to make it posible, Manheim incidentally considered social justice to be absolutely imperative. An excessive degree of inequality in income, assets, educational opportunity, employment, and nutrition undermines consensus and thereby democracy too" (Blokland, 2001). El compromiso ético de las élites políticas con respecto al fortalecimiento democrático, requiere la puesta en marcha de aquellos mecanismos de protección social, inclusión y empoderamiento necesarios para permitir, desde la igualdad de oportunidades, la equidad en el acceso a los procesos participativos desde el conocimiento de las instituciones, así como la adquisición y desarrollo de las habilidades dialécticas y formativas con respecto a las posibilidades de inclusión y participación en los procesos de adopción de decisiones.

\subsection{El fortalecimiento democrático como postulación primordial en los procesos de adopción de decisiones frente a la crisis económica y sus consecuencias sociales e institucionales}

Desde un punto de vista aristotélico, el obrar ético implica la consecución del fin mediante una conducta teleológicamente acorde con la naturaleza de tal fin. En este sentido, la promoción de la democracia como fin y valor superior requiere del desarrollo de la misma, en tanto que medio, en el proceso de su consecución y realización final. Es de esta forma como cualquier problema de democracia, no pudiendo sino ser sino abordado con la propia democracia (es decir, con más democracia), no cabe alegar excepción cesarista alguna a la hora de pretender un fortalecimiento de la democracia, a costa de un sacrificio temporal, paternalista, de la misma, por muy acuciantes e inciertas que sean las circunstancias, las demandas ciudadanas y la necesidad de las élites políticas por ofrecer soluciones o, al menos, por generar percepción de que dichas soluciones están siendo adoptadas. La democratización de la gestión pública constituye uno de los pilares esenciales para evitar, en primer lugar, la apatía política, resultando necesario romper la desacertada dicotomía entre la participación ciudadana y los procesos representativos clásicos (pues ambos se fortalecen recíprocamente) $\mathrm{y}$, en segundo lugar, avanzar en la transparencia y el grado de apertura de las políticas públicas, debiendo los gobiernos: “(...) ampliar bastante su papel pedagógico en relación con la participación ciudadana, sin que ello signifique perder la autonomía de la sociedad" (CLAD, 2011). La implementación de mecanismos de participación ciudadana deliberativa que complementen los instrumentos representativos, ha supuesto la generación de múltiples reflexiones dirigidas a legitimar tales mecanismos y a proponer modelos de viabilidad y articulación de los mismos. Así, observamos el desarrollo de una formulación de la ética del diálogo, respecto de la cual: “(...) no se niega ni se prejuzga la posibilidad de que estas decisiones puedan tomarse por consenso, pero lo importante no es el resultado, sino la aceptación del diálogo como vía, de la composición de pareceres sobre la base del intercambio de informaciones y posturas [Prieto, 2003]" (García Alonso, 2012). La 
generación de consensos acerca de los fundamentos éticos de las instituciones y de los procesos de interacción social en los sistemas participativos y deliberativos, requiere una metodología ciertamente compleja por cuanto se refiere a la pluralidad y complejidad axiológica ya señalada. Tal consenso no debe fijarse sólo sobre el output de los procesos de decisión, sino sobre los parámetros normativos que regirán el propio proceso de decisión conforme a la fórmula del consenso normativo y que permite sostener la premisa de que: "dialogue is at the heart of a conception of democracy that privileges discussion as a means of expanding social understanding and solving collective problems" (Maddison, 2012). Ello remite, de forma directa, a la legitimidad del propio entramado institucional en que subliman, institucionalmente, las reglas y los procesos participativos. Siguiendo a Meyer y Scott (1983), la legitimación organizacional es: “(...) the degree of cultural support for an organizations -the extent to which the array of established cultural accounts provide explanations for its existence, functioning, and jurisdiction, and lack or deny alternatives" (Meyer y Scott, 1983). Plunkett (2011), ofrece un modelo integrado de "legitimacy judgements" desde la perspectiva conjunta de la Teoría Institucional y la Psicología Política, mientras que Ehrich, Cranston y Kimber (2004) ofrecen un modelo útil para identificar la naturaleza de los dilemas éticos y las fuerzas que impactan sobre las elecciones que realizan los gestores públicos en la práctica (Ehrich, Cranston y Kimber, 2004). Partiendo de la moralidad en tanto que un rasgo de nuestra autonomía racional, y considerando las actuales circunstancias de diversidad social y axiológica, Smith y Dubbink (2011) sostienen que tal escenario: "(...) transforms the process of moral judgement into a joint or social phenomenon where the suggestions, criticisms, needs and interests of others who are affected by one's judgement inform the creative implementation of moral principles (...)" (Smith y Dubbink, 2011). Sen (2003) señala la vinculación del comportamiento a estándares de ética y moralidad a partir de dos enfoques: “(...) el razonamiento ético en nombre de la sociedad y, por la otra, relacionarse con la elección, razonada o por inclinación, inspirada en la supervivencia evolutiva vinculada a beneficios individuales a largo plazo y al éxito social" (Sen, 2003).

En el escenario del nivel de gobierno local y en un contexto de crisis, Pollit (2010) sugiere algunas consideraciones que podrían guiar las decisiones adoptadas por los líderes políticos en el marco de la presente circunstancia financiera y socioeconómica, entre las que se encontraría la ética respecto al modo de emprender los procesos presupuestarios de ajuste, bajo parámetros de participación, transparencia y honestidad sobre las intenciones y los resultados esperados (Pollit, 2010). Las cuatro líneas serían: 1. "Timming", teniendo en consideración la perspectiva a largo plazo de cualquiera que sean los cambios a adoptar, incluyendo los esfuerzos para cambiar las culturas del servicio público; 2. "Ethics", en tanto al modo de emprender los procesos presupuestarios de ajuste, bajo parámetros de participación, transparencia y honestidad sobre las intenciones y los resultados esperados; 3 . "Strategy and communications"; y, 4. "Legitimacy", por cuanto la actual situación constituye, no sólo una crisis económica de corte financiero sino, además, una crisis de legitimidad (Pollit, 2010). La participación y la inclusión ciudadana en los procesos de adopción de decisiones frente a la crisis en el marco de realidades locales específicas, sin que esta premisa sirva de excusa para justificar y legitimar clientelismos y exclusivismos localistas, permite evitar procesos de decoupling, los cuales refieren al eventual desajuste o gap entre: 1. Los outputs institucionales derivados de un determinado proceso de reforma y transformación, y 2. Las prácticas efectivamente aceptadas y desarrolladas por los distintos actores de la comunidad local, tanto a nivel cívico y social, como institucional y 
gubernamental. De acuerdo con Ramió (2010): “El decoupling genera así una suerte de organización informal, una determinada interpretación de las instituciones, que se corresponde con los valores, pautas de conducta y procesos de trabajo habituales en el contexto organizativo en el que se aplican" (Ramió, 2010). Si bien, en el ámbito de las políticas de codificación de la ética, Jovanovic y Wood (2007) observan efectos positivos derivados de los fenómenos de decoupling, a saber: “(...) when organizational members engage in discussions that turn away from the letter of an ethics code they often do so to address higher ethical principles embedded in the spirit of the code" (Jovanovic y Wood, 2007). Así, la determinación deliberativa de los objetivos o mandatos de gestión, que constituyen puntos de partida, no devienen en fines en sí mismos (Kelly, Mulgan y Muers, 2002).

En definitiva, la "democracia deliberativa, el republicanismo cívico y el patriotismo constitucional", siguiendo a Menéndez Alzamora (2012), permiten materializar las tendencias dirigidas a fortalecer la participación de los ciudadanos en el diseño, implementación, control y evaluación de las políticas públicas, en un contexto, no obstante, de apatía en el que: “(...) la ciudadanía ha dado la espalda a la esfera pública en el marco de una globalización que cuestiona el modelo nacional en el que estas propuestas se han construido en los dos últimos siglos" (Menéndez Alzamora, 2012). La adopción de tales procesos inclusivos implica incardinar la deliberación entre dos puntos de equilibrio, armonizando tolerancia y convicción moral de una parte, y delineando por otra parte un encuentro entre: “(...) a politics of common sense preoccupied with everyday issues, and a politics of reason proposing total solutions to historial and social issues" (Dayllmayr, 1974). En sociedades plurales desde un punto de vista moral y axiológico y, en un contexto, en definitiva, donde conviven diferentes morales de máximos, la asunción de los parámetros éticos de referencia requiere de: “(...) procesos de deliberación en la esfera pública para ir descubriendo los valores y principios de una ética cívica común a los distintos grupos. En sociedades moralmente republicanas el proceso de deliberación en la esfera pública es esencial para decidir conjuntamente acerca de lo justo y de lo injusto, de lo correcto y de lo incorrecto" (Cortina, 2002).

\section{CONCLUSIONES}

\section{Ethics in local government: it's more than not doing bad things}

El documento Ethics in the Public Service. Current Issues and Practice (OCDE, 1996) vino a incidir en una noción de la Ética Pública no únicamente centrada en el control y la restricción punitiva de las conductas contrarias a los principios éticos codificados, sino, fundamentalmente, en una perspectiva basada en la promoción de la integridad y las buenas conductas (OCDE, 1996), lo cual permite remitir a la noción de prevención (Langford, 1991) y promoción positiva de la Ética Pública. En última instancia, el debate continúa siendo si la efectividad de los instrumentos de gestión de la integridad dependen de su carácter sancionador o incentivador o, en su caso, de la naturaleza más o menos exhaustiva en su regulación y concreción propositiva (Demmke y Moilanen, 2012) y, en última instancia, en función de si tales documentos determinan lo que no se debe hacer (limitativa y negativamente) o, por el contrario, lo que se debe hacer (positivamente). Demmke y Moilanen (2012), enumeran un conjunto de instrumentos éticos impulsados por parte de los Estados Miembros de la UE-27: "Rules, Standards, Codes; Value Management; Ethical 
Leadership; Whistle-blowing; Disciplinary rules; Job Rotation; Risk Analysis of vulnerable positions; Training and Dilemma Training; Integrity Plans; Scandal Management; Audits; Integrity Officers; Registers of Interest; Transparency requirements; Internet based selfassessments; Ethics climate survey; Awareness raising instruments" (Demmle y Moilanen, 2012). En el número de Julio de 2004 de la revista estadounidense Public Management, aparecía publicado el artículo "Ethics in local government: it's more than not doing bad things" (Carlee, 2004). Quizás sea esta la más lacónica y elocuente expresión de la noción que sobre la Ética Pública cabe desear y configurar más allá de la noción limitativa-negativa de la misma en cuanto que punitiva de las conductas reprochables y contrarias, no sólo con respecto al ordenamiento disciplinario y jurídico en lo administrativo y en lo penal (tal que "stealing, lying, cheating, favoritism, self-aggrandizement, and profiting from our positions" (Carlee, 2004)). Nos referimos, en particular, a la promoción propositiva de: 1. La deontología profesional de los empleados públicos; 2. La promoción de los principios constitucionales conforme al artículo 9 de la Constitución Española; y, 3. La ejemplaridad pública asumido desde el liderazgo por parte de electos.

En este punto, es obligada la tarea de abordar la Ética Pública a partir de la bifurcación de la misma en sus manifestaciones; a saber, la ética en su expresión negativa, en tanto que limitadora y punitiva de las conductas definidas a priori contrarias a los principios éticos y de conducta; y, la positiva, destinada a la promoción de las conductas, acciones y medidas individuales o colectiva que tienen por objeto la consecución y la promoción de los bienes ligados a la integridad, la Ética Pública y el Buen Gobierno. Estas dos formulaciones han sido conceptualizadas por la OCDE (1996), y en base a las mismas, se han generado sendos modelos de gestión de la integridad: A. De una parte, los modelos Integrity-based, se centran en una noción de la ética fundamentada en aquello que se debe hacer, de las conductas a promover, impregnados por una filosofía fundamentada en los resultados de gestión, más que en los procedimientos. Los tres pilares sobre los que se erige dicha formulación son: 1) "(...) the definition of overall aspirational "values" for the public sector or the "high road" (sometimes supplemented by decentralised codes of conduct reflecting the specific mission of relevant organisations); 2) a focus on what is achieved rather than how it was achieved (that is, a focus on ends rather than means); y, 3) an emphasis on encouraging good behaviour rather than policing and punishing errors or bad behaviour" (OCDE, 1996). B. Por el contrario, los sistemas deontológicos o "Compliance-based" se centran en determinar: "(...) with administrative procedures and detailed rules (often codified in legislation) which define what public servants should do and how. In this context, the focus of codes of conduct is often on the negative, that is, what public servants should not do and what sort of behavior they should avoid (OCDE, 1996)". Tal y como hace constar la OCDE en el documento Public Management Occasional papers, $n^{o}$ 14, Ethics in the Public Service: Current Issues and Practice (OCDE, 1996), se trata de enfatizar: "(...) on encouraging good behaviour rather than policing and punishing errors or bad behaviour" (OCDE, 1996). Si bien, la adopción de este integrity-based model, requerirá, para su exportación más allá del ámbito mayoritariamente anglosajón, interponer determinadas revisiones y actualizaciones adaptativas con objeto de hacer viable tal enfoque en contextos institucionales y de cultura política de distinta tradición jurídica y política (v. gr., europea continental). Y es que resulta preciso no ignorar la correlación entre los modelos de gestión de la integridad y los contextos administrativos en los que se implantan. Así, los integrity-based model se ligan a los sistemas de Nueva Gestión Pública, mientras que los Compliance-based models disponen de mayor capacidad de arraigo en los sistemas de Administración Pública Tradicional (Mariñez 
Navarro, 2011). Si bien, un tercer modelo viene dado por el de la Generación de Valor Público (Kelly, Mulgan y Muers, 2002), en el que, siguiendo a Mariñez Navarro, (2011): “en esta tendencia de gestión pública, se ubica una Ética Pública basada en la conjunción de la libertad individual y civil con la autoridad legítima del Estado que exige participación democrática, donde la rendición de cuentas y la participación ciudadana son elementos clave" (Mariñez Navarro, 2011). La Federación Española de Municipios y Provincias (FEMP), a través de su Comisión Ejecutiva y del Consejo Federal, procedió a la adopción del Código de Buen Gobierno y que, de acuerdo con su Preámbulo, se constituye: “(...) de una serie de principios y el diseño de instrumentos de gobierno, que contribuyan a consolidar pautas de comportamiento de los representantes locales en aras a configurar una Ética Pública común que evite la mala gestión, destierre posibles actuaciones corruptas, y por el contrario sirva para generalizar las buenas prácticas" (FEMP, 2009). El código contempla seis bloques en los que se desarrollan: 1. Principios del Código del Buen Gobierno Local. 2. Medidas para mejorar la gestión y la calidad de la democracia local. 3. Incompatibilidades y declaraciones de actividades de bienes. 4. Retribuciones económicas de los electos. 5. Medidas de democracia participativa; y, 6. Mecanismos para su aprobación, difusión y cumplimiento (FEMP, 2009).

En definitiva, siendo la gestión de la crisis un reto estructural dados los factores de urgencia y debido a la complejidad de su faz poliédrica, resulta preciso asumir la emergencia de la ética en el sentido en que esta se expresa informando procesos de fortalecimiento normativo, axiológico e institucional a largo plazo. De ahí que no sólo baste con sanciones, que sin duda alguna permiten la efectividad de los códigos sobre Ética Pública y garantizan su plena vigencia mediante la punición. Pues en última instancia, siguiendo a Manske, y Frederickson, (2004): "Even the finest code of ethics would be rendered ineffective if government officials did not understand its provisions or why those provisions were there and what their importance was" (Manske, y Frederickson, 2004).

\section{BIBLIOGRAFÍA}

ALTÉS MARTÍ, M. A.; BAÑOS ALONSO, J. R. y NÚÑO DE LA ROSA AMORES, J. A. (2011), El Código Penal de 1995 y sus posteriores reformas, Valencia, Tirant lo Blanch.

AMEER, R. y OTHMAN, R. (2012), "Sustainability Practices and Corporate Financial Performance: A Study Based on the Top Global Corporations" en Journal of Business Ethics, Vol. 108 (1), pp. 61-79.

ANECHIARICO, F. y JACOBS, J.B. (1994), "Visions of Corruption Control and the Evolution of American Public Administration", en Public Administration Review, Vol. 54 (5), pp. 465-473.

ARANGUREN, J. L. (2011), Ética y política, Madrid, Diario Público.

ARGANDOÑA, A. (2010), "La dimensión ética de la crisis financiera" en Cátedra "la Caixa" de Responsabilidad Social de la Empresa y Gobierno Corporativo. IESE Business School-Universidad de Navarra, Barcelona, Documento de Investigación DI-872.

ATKIN, N. (2003), "Ethics and Public Relations from an Assessment Perspective", en Assessment Journal, Winter, pp. 41-51.

ÁVILA RODRÍGUEZ, C. y GUTIÉRREZ RODRÍGUEZ, F. (coords.) (2011), El derecho a una buena administración y la ética pública, Valencia, Tirant lo blanch.

BECKETT-CAMARATA, J. (2009), "Local government measurement and use of performance accounting and financial reporting data in planning and budgeting decision support: a multicase study", en Public performance y management review. Vol. 33 (10, 2), pp. 255-265. 
BENNET. S. E., FISHER, B. y RESNICK, D. (1996), "Speaking of politics in the United States: Who talks to whom, why, and why not?", en Poznan Studies in the Philosophy of the Sciences and the Humanities, Vol. 46, pp. 263-293.

BLOKLAND, H. (2001), Modernization and its Political Consequences. Weber, Manheim and Schumpeter, London, University Press.

BLOSCA LÓPEZ, F. J. (2010), "La apariencia de control en la administración local por los habilitados estatales", en Auditoría Pública, no 52, pp. 71-78.

CANALES ALIENDE, J. M. (2002), "Algunas reflexiones sobre la ética pública", en VII Congreso Internacional del CLAD sobre la Reforma del Estado y de la Administración Pública, Lisboa, Portugal, 8-11 Octubre.

CANALES ALIENDE, J. M. (2011), “Crisis y Administración pública”, en El Mundo (Tribuna Invitada), 18 de septiembre.

CARLEE, R. (2004), "Ethics in local government: it's more than not doing bad things", en Public Management, Vol. 86 (6).

CHANDEL, N. (2012), "Administrative Ethics and Culture of District Officers", en IPSA-World Congress, RC 48 Panel 1: Ethics in Public Administration, including corruption/anti-corruption.

CIULLA, J. B. (2004), Ethics, the heart of leadership, London, Praeger.

CLAD (2011), "Gestión Pública Iberoamericana para el siglo XXI", en Revista del CLAD Reforma y Democracia, n 50, pp. 191-226.

CORTINA, A. (1998), Hasta un pueblo de demonios. Ética pública y sociedad, Madrid, Taurus.

CORTINA, A. (2002), "La Dimensión Pública de las Éticas Aplicadas", en Revista Ibero Americana de Educación, n' 29 , pp. 45-64

CORTINA, A. (2007), Ética aplicada y democracia radical, Madrid, Tecnos.

CORTINA, A. (2012), "Ética en tiempos de crisis", en El País, 2 julio, disponible en: http://elpais.com /elpais/2012/06/13/opinion/1339587064_162579.html.

COWELL, R., DOWNE, J. y MORGAN, K. (2011), "The Ethical Framework for Local Government in England: is it having any effect and why?", en Public Management Review, 13(3), pp. 433-457.

DAYLLMAYR, F. R. (1974), "Toward a Critical Reconstruction of Ethics on Politics" en The Journal of Politics, Vol. 36 (4), pp. 926-957.

DEMMLE, C. y MOILANEN, T. (2012), Effectiveness of Ethics and Good Governance in Central Administration of EU-27: Evaluating Reform Outcomes in the Context of the Financial Crisis, Oxford, Peter Lang.

DIEGO BAUTISTA, O. (2009), "Institucionalización de la Ética en el ámbito de Gobierno”, en Cuadernos de ética para los servidores públicos, Toluca, México, ANCoPLe.

DIEGO BAUTISTA, O. (2009), Ética para corruptos. Una forma de prevenir la corrupción en los gobiernos y administraciones públicas, Urduliz, Desclée De Brouwer, S. A.

DORNA, A. (1997), "Elementos para una psicología política del fascismo", en Psicología Política, no. 15, pp. 69-93.

EHRICH, L., CRANSTON, N. y KIMBER, M. (2004), "Public sector managers and ethical dilemas", en Journal of the Australian and New Zealand Academy of Management, 10 (1), pp. 25-37.

EUDEL (2011), Guía para la Elaboración de un Plan de Acción Municipal ante la Crisis Económica, Bilbao, Euskadiko Udalen Elkartea-Asociación de Municipios Vascos.

EWING, A. C. (1941), "Political Arguments: Politics and Ethics", en Philosophy, Vol. 16 (62), pp. 138150.

FEMP (2009), Código de Buen Gobierno Local, Madrid, Federación Española de Municipios y Provincias (FEMP).

FONT I LLOVET, T. y GALÁN GALÁN, A. (2008), "Desarrollo estatutario y gobierno local: en tiempos de tribulación... hacer mudanzas", en Anuario del Gobierno Local. Fundación Democracia y Gobierno Local - Institut de Dret Públic, pp. 13-30.

FRANKLIN, A. L., y RAADSCHELDERS, J. C. (2004), "Ethics in local government budgeting: Is there a gap between theory and practice?", en Public Administration Quarterly, 27(4), pp. 456-490. 
FRASER, N. (1992), "Rethinking the Public Sphere: A Contribution to the Critique of Actually Existing Democracy", en C. Calhoun (ed.), Habermas and the Public Sphere, Cambridge, MIT Press. FUKUYAMA, F. (2012), "The Future of History. Can Liberal Democracy Survive the Decline of the Middle Class?", en Foreign Affairs, 91 (1), pp. 53-61.

GARCÍA, R. (2012), "Racionalidad individual y dinámicas de grupo: limites y posibilidades para una lectura deliberativa de la democracia", en IPSA-Wold Congress, panel: Deliberative Democracy: Theoretical Perspectives.

GIOVANOLA, B. (2011), "Ethics and Public Administration: On the Italian Case and Beyond", en International Journal of Public Administration, Vol. 34 (1/2), pp. 59-67.

GRIMES, M. y BAUHR, M. (2012), "What is Government Transparency? New Measures and Relevance for Promoting Better Government", en IPSA-Wold Congress, panel: Ethics in Public Administration, including corruption/anti-corruption.

GUIU, J. (1999), "El socialismo", en M. Caminal Badía (ed.), Manual de Ciencia Política, Madrid, Tecnos.

HO, ALFRED TAI-KEI (2000), "Balanced Ethical Perspective to State and Local Economic Development Policies", en Global Virtue Ethics Review, Vol. 2 (2).

HOOGLAND, R. y WHITAKER, G. P. (1993), "Professional Leadership in Local Government", en International Journal of Public Administration, $\mathrm{n}^{\circ}$ 16, pp. 2023-2049.

INGLEHART, R. (1991), El cambio cultural en las sociedades industriales avanzadas, Madrid, Centro de Investigaciones Sociológicas (CIS).

JIMÉNEZ ASENSIO, R. (2011), "Las instituciones locales en tiempo de crisis: reforma institucional y gestión de recursos humanos en los Gobiernos locales", en QDL, Fundación Democracia y Gobierno, 25, pp. 57-77.

JOVANOVIC, S. y WOOD, R. V. (2007), "Dialectical interactions: decoupling and integrating ethics in ethics initiatives", en Business Ethics Quarterly, Vol. 17 (2), pp. 217-238.

KELLY, G., MULGAN, G. y MUERS, S. (2002), "Creating Public Value: An Analytical Framework for Public Service Reform", Discussion paper prepared by the Cabinet Office Strategy Unit, United Kingdom (UK).

KIDDER, R. M. (1995), “Universal Human Values: Finding an Ethical Common Ground”, en J. Wren, Leader's Companion, New York, The Free Press.

LANCER JULNES, P. (2009), "The role of performance measurement in ethical and effective government", en XIV Congreso Internacional del CLAD sobre la Reforma del Estado y de la Administración Pública, Salvador de Bahía, Brasil, 27-30 Oct.

LANGFORD, J. (1991), "The International Experience: Reflections on the Way Ahead", en Proceedings of a Royal Australian Institute of Public Administration Seminar "Do Unto Others: Ethics in the Public Sector", pp. 14-23.

MADDISON, S. (2012), "Democratic dialogue: An exercise in deliberation or agonism?", en IPSAWold Congress, panel: Deliberative Democracy: Theoretical Perspectives.

MANHEIM, K. (1941), "Diagnosis of Our Time", en K. Manheim, Diagnosis of Our Time: Wartime Essays of a Socilogist, London, Kegan Paul, Trench, Trubner.

MANSKE, M. W. y FREDERICKSON, H. G. (2004), "Building a Strong Local Government Ethics Program", en Public Management, Vol. 86 (5), pp. 18-22.

MARIÑEZ NAVARRO, F. (2011), "Reflexiones sobre las éticas en la gestión pública", en Administración y Desarrollo, Vol. 39 (54), pp. 85-98.

MARSH, D. y STOKER, G. (eds.). (1997), Teoría y métodos de la ciencia política, Madrid, Alianza. MENÉNDEZ ALZAMORA, M. (2012), "Democracia deliberativa, republicanismo cívico y patriotismo constitucional", en IPSA-Wold Congress, panel: Deliberative Democracy: Theoretical Perspectives. MEYER, J. y SCOTT, R. (1983), Organizational environments: Ritual and rationality, Beverly Hills, Sage.

MOE, R.C., y GILMOUR, R.S. (1995), "Rediscovering principles of public-administration: The neglected foundation of public-law", en Public Administration Review, 55(2), pp. 135-146.

MOORE, B. (1966), The Social Origins of Dictadorship and Democracy, Boston, Beacon Press. 
MOORE, M. H. (1981), "Realms of Obligation and Virtue," en J. Fleishman; L. Liebman; H. Mark y M.H. Moore, (eds.), Public Duties: The Moral Obligations of Government Officiats, Cambridge, Harvard University Press.

OCDE (1996), Ethics in the Public Service. Current Issues and Practice. Fighting corruption in the public sector, OCDE.

OCDE (2000), "Building Public Trust: Ethics Measures in OECD Countries", PUMA Policy Brief $\mathrm{n}^{\circ} 7$.

OCDE, (2009), Recommendation of the Council on Enhancing Integrity in Public Procurement (Decisions, Recommendations and other Instruments of the OECD, Public Governance Committee), en http://acts.oecd.org/.

OKAMOTO, M. (2012), “Municipal Amalgamation in Japan: Who Is Happy?", en IPSA-Wold Congress, Session: Comparative Studies on Local Government and Politics, en http://www.ipsa.org/ my-ipsa/even ts/madrid2012/paper/municipal-amalgamation-japan-who-happy.

PLUNKETT, T. (2011), "An Integrative Model of Legitimacy Judgments", en Academy of Management Review, 36, pp. 686-710.

POLLIT, C. (2010), "Public Management reform during financial austerity", en Statskontoret: Swedish Agency for Public Management.

POLLIT, C. y BOUCKAERT, G. (2011), Public Management Reform. A comparative analysis, New Public Management, Governance, and the Neo-Weberian State, Oxford, Oxford University Press.

PRESTON, N. y SAMFORD. C, (2002), Encouraging ethics and challenging corruption, Sydney, The Federation Press.

PRZEWORSKI, A., et al. (1996), "Las condiciones económicas e institucionales de la durabilidad de las democracias", en La Política: Revista de estudios sobre el estado y la sociedad, n 2, pp. 89-108.

RAMIÓ, C. (2010), "La gestión pública en tiempos de crisis", en Revista Venezolana de Gestión Pública, Año 1, nº 1, pp. 17-34.

RODRÍGUEZ ÁLVAREZ, J. M. (2010), "Estructura institucional y organización territorial local en España: fragmentación municipal, asociacionismo confuso, grandes ciudades y provincias supervivientes", en Política y Sociedad, Vol. 47 (3), pp. 67-91.

RUIZ GARIJO, M. (2012), "Más de diez años de Responsabilidad Social Corporativa. ¿Para cuándo su regulación jurídica y el establecimiento de incentivos fiscales", en Revista Vasca de Economía Social, no 7, pp. 29-49.

RUSSELL, B. (1987), Sociedad Humana: ética y política, Madrid, Cátedra.

SADOWSKI, S. T. y THOMAS, J. R (2012), "Toward a Convergence of Global Ethics Standards: A Model from the Professional Field of Accountancy", en International Journal of Business and Social Science, Vol. 3 (9), pp. 14-20.

SALVADOR CRESPO, M. T. (2009), "El gobierno y la administración local en España tras 30 años de ayuntamientos democráticos", en Revista general de derecho constitucional, $\mathrm{n}^{\mathrm{o}}$ 8, pp. 1-28.

SANMARTÍN, J. (2012), "El autoritarismo de la nueva ultraderecha europea como amenaza para la seguridad democrática", en IPSA-Wold Congress, panel: Análisis estratégico e inteligencia en un mundo globalizado, disponible en: http://www.ipsa.org/my-ipsa/events/madrid2012/paper/el-autoritaris mo-de-la-nueva-ultraderecha-europea-como-amenaza-para-.

SEN, A. (1999), Development as Freedom, Oxford, Oxford University Press.

SEN, A. (2003), “QQué impacto puede tener la ética?", en Seminario Internacional "Ética y Desarrollo", Banco Interamericano de Desarrollo.

SMITH, J. y DUBBINK, W. (2011), "Understanding the Role of Moral Principles in Business Ethics", en Business Ethics Quarterly 21 (2), pp. 205-231.

STEPHEN I. (2010), "Ethics Management as an Important Aspect of Democratic Development and Public Administration: A Case Study of Tanzania", en 62nd Annual Conference, "Guardians of Our Communities, from Local to Global", The Institute of Public Administration of Canada.

SUÁREZ, J. (2011), "Crisis económica y reforma de la Hacienda Local", en III Jornada de Administración Local, "La financiación y las competencias municipales a debate", Teatro de Lloseta, 4 de marzo de 2011. 
TOMÀS, M. y MEDIR, L. (2012), "Local Government Amalgamation and its Alternatives: Effects on Democracy and Governance", en IPSA-Wold Congress, Session: Comparative Studies on Local Government and Politics, en http://www.ipsa.org/my-ipsa/events/madrid2012/paper/cooperationversusamalgamation-cases-barcelona-and-montreal.

TORCAL, M. (1989), "La dimensión materialista/postmaterialista en España: Las variables del cambio cultural”, en Revista Española de Investigaciones Sociológicas, 47, pp. 227-254.

VILLORIA, M. (2011), "La ética pública y los códigos de conducta administrativos vs. corrupción y escándalos politicos", en C. Ávila Rodríguez y F. Gutiérrez Rodríguez (coords), El derecho a una buena administración y la ética pública, Valencia, Tirant lo blanch, pp. 179-202.

VILLORIA. M. (2000), Ética pública y corrupción: Curso de ética administrativa, Madrid, Tecnos.

WEBER, M. (2010), La ética protestante y el "espiritu" del capitalismo, traducción, nota preliminar y glosario de Joaquín Abellán, Madrid, Alianza Editorial.

WEINGAST, B. (1997), “The Political Foundations of Democracy and the Rule of Law", en American Political Science Review, Vol. 91 (2), pp. 245-263.

WELZEL, C. y INGLEHART, R. (2009), "Mass Beliefs and Democratic Institutions", en S. Stokes y C. Boix, The Oxford Handbook of Comparative Politics, Oxford, Oxford University Press.

WHITELEY, P. (2011), “Are Britons Getting More Dishonest?", Documents / Papers: University of Essex, en http://www.essex.ac.uk/government/documents/are_britons_etting_more_dishonest.pdf

WILDAVSKY, A. (1974), The Politics of the Budgetary Process, Boston, Brown.

WILLIAMS, R. y ELLIOT, L. (2010), Crisis and Recovery, Hampshire, Palgrave MacMillan.

\section{Breve currículo}

\section{Bernabé Aldeguer Cerdá}

Licenciado en Ciencias Políticas y de la Administración. Premio Extraordinario de Licenciatura, Certificado de Excelencia Académica (Generalitat Valenciana) y Mención Especial del Ministerio de Educación (Gobierno de España). Máster en Gestión Pública y Liderazgo Político (Universidad de Alicante) y Máster Universitario de Profesores de Educación Secundaria Obligatoria y Bachillerato, Formación Profesional y Enseñanza de Idiomas (UMH). Diplomado por la Escuela de Métodos de Análisis Sociopolítico (USAL) y por el Ilustre Colegio Nacional de Doctores. Diplomado por la University of Essex, por la Harvard University-Real Colegio Complutense-CIS, por el "X Seminario Giménez Abad sobre el Parlamento" y por el ECPR - Universidad de Viena. 